Revista de Filología Románica

ISSN: 0212-999X

http://dx.doi.org/10.5209/RFRM.58169

\title{
Semblanza de D. Alonso Zamora Vicente
}

Juan Mayor Sánchez ${ }^{1}$

Recibido: 20 de febrero de 2017 / Aceptado: 4 de octubre de 2017

Resumen. Se analiza en este texto la personalidad de Alonso Zamora Vicente y se la relaciona con las diferentes actividades que realizó durante su vida: docente, investigadora, creadora o de gestión. Se destaca, asimismo, su talante comunicativo y su ironía, que se plasma en su obra y en el contacto con los alumnos, como la anécdota que se incluye en el texto. Se finaliza, por último, valorando su compromiso histórico con los tiempos que le tocaron vivir.

Palabras clave: Alonso Zamora Vicente; personalidad de Alonso Zamora Vicente; El Gallo.

\section{[en] Alonso Zamora Vicente, a Profile}

\begin{abstract}
This article analyses Alonso Zamora Vicente's personality and relates it to the different Teaching, research and administrative activities that he carried out throughout his life. His irony and talent for communication are also highlighted both in his work and in his contact with students (plus an anecdote which is included in this profile). A conclusion focuses on his historical engagement with the times he lived in.
\end{abstract}

Keywords: Alonso Zamora Vicente; Alonso Zamora Vicente's personality; El Gallo.

Sumario: 1. Presentación; 2. Algunas características de Alonso Zamora Vicente; 3. La importancia de la lengua en la vida y obra de Alonso Zamora Vicente; 4. Alonso Zamora Vicente y su inserción en el contexto histórico; 5. Referencias bibliográficas; 6. Apéndice.

Cómo citar: Mayor Sánchez, J. (2017). Semblanza de D. Alonso Zamora Vicente, en Revista de Filología Románica 34. Núm. especial, 197-202.

\section{Presentación}

Buenos días a todos y buen día para recordar a un hombre excepcional que, por suerte, fue para muchos de nosotros un querido y admirado maestro, Alonso Zamora Vicente.

Mi homenaje a él en este acto va a ceñirse a lo que nos pide la primera acepción de semblanza (según el Diccionario de la RAE), es decir, "bosquejo biográfico", con todo lo que ello tiene de aproximativo y parcial, aunque me base en mi experiencia

1 Profesor emérito de la Universidad Complutense de Madrid

E-mail: jmaydelcampo@yahoo.es 
personal, en datos objetivos ampliamente conocidos y en algunas manifestaciones publicadas del propio D. Alonso.

\section{Algunas características de la personalidad de Alonso Zamora Vicente}

Intentaré en esta breve y particular semblanza destacar algunas características de su personalidad y de su conducta, es decir, de su actividad a lo largo de su vida. En cuanto a su personalidad, recurriremos a la vieja, pero todavía vigente, distinción de Jung o de Eisenck entre personalidad introvertida y extrovertida. Don Alonso reúne las características de la persona extrovertida, que se mueve en dirección a la gente, hacia lo objetivo, hacia una vida centrada en la acción. Todos sus alumnos y las gentes de los barrios populares de Madrid lo han podido comprobar. Si tomamos en cuenta la tipología sobre formas de vida que propuso Spranger: seis tipos de homo, theoreticus, aeconomicus, aestheticus, socialis, politicus y religiosus, tendríamos que convenir que no encaja completa y exclusivamente en ninguno de esos tipos de hombre. La razón estriba en que su personalidad es compleja y se ajusta tanto al homo theoreticus, como al homo aestheticus y al homo socialis. Pero las características que corresponden a estas formas de vida en él no se suman simplemente las unas a las otras, sino que se enlazan entre sí, son interdependientes y, en conjunto, constituyen esa estructura compleja que es la que define al verdadero D. Alonso. En lo que sigue veremos abundantes ejemplos de ello.

Si pasamos a analizar su conducta, sus hechos, su tarea, su obra, encontramos también unas constantes que contribuyen decisivamente a dibujar el retrato de su vida. Una de ellas es el tipo dominante de su actividad: su dedicación al trabajo como "acción y efecto de trabajar" (Diccionario de la RAE), es decir, "ocuparse en cualquiera actividad física o intelectual" (Diccionario de la RAE). Por su dominio casi aplastante en la vida de D. Alonso, la actividad, el trabajo, la tarea de la que tenemos que ocuparnos es inequívocamente intelectual. Él lo formuló como propósito y como regla: "hay que llenar el vivir con la tarea elegida y ocuparnos y preocuparnos de ello" (Zamora Vicente 1958:11).

Como es bien sabido su tarea principal fue la de enseñar y por eso fue profesor en todas las ocasiones que se le presentaron o que buscó: institutos de todo tipo, universidades (sobre todo, Santiago, Salamanca, Madrid, Buenos Aires, México), centros e instituciones de Alemania, Austria, Bélgica, Checoslovaquia, Estados Unidos, Finlandia, Francia, Holanda, Inglaterra, Italia, Portugal, etc... Pero no podemos olvidar que, junto a la actividad de enseñar, llevó a cabo un trabajo constante de observar, de adquirir conocimientos, de estudiar y de realizar diferentes y numerosísimos tipos de investigación (con frecuencia en los lugares antes citados). Realizó también actividades de gestión relacionadas con las anteriores y, muy especialmente en la RAE como miembro numerario, y, sobre todo, como secretario de la misma. Asistió a numerosos congresos y reuniones de trabajo de todo tipo. Pero hay que destacar especialmente el trabajo callado y constante dedicado a escribir libros científicos y de divulgación, así como diversos tipos de narraciones (cuentos, textos de difícil catalogación como estampas de la calle y de la gente, esbozos de personajes, escenas costumbristas), publicadas en revistas y periódicos, pero también reunidos en numerosos libros. 
Con esta enumeración de actividades he querido destacar el tiempo, la dedicación y el esfuerzo que conlleva ese trabajo. El resumen es que D. Alonso ha sido un trabajador incansable, concienzudo e ilusionado. Él mismo reconoce: "en nuestros años universitarios teníamos la preocupación por saber, por conocer, por instalarnos en un mundo intelectual que nos abría las puertas generosamente y que, a cambio, pedía de nosotros trabajo, constancia y entusiasmo" (Zamora Vicente 1993:38). Es evidente la respuesta positiva que dio a esa petición. Pero, además, confiesa en otra ocasión que "mi trabajo me ha producido hondas satisfacciones", pero añade: "también, qué duda cabe, han menudeado desazones; es claro, la vida es una tenaz sucesión de logros y fracasos, de síes y de noes, y así hay que aceptarla" (Zamora Vicente 1993:3).

Una segunda característica de la actividad de D. Alonso es el tipo o modalidad de esa actividad. En lo anterior hemos aludido implícitamente a ella, pero ahora queremos referirnos a ella explícitamente: se trata de la actividad comunicativa. En casi todos los trabajos antes citados se pone en evidencia que se trata de actividades llevadas a cabo con un talante comunicativo caracterizado por la apertura y el interés por el otro. Incluso cuando escribe una narración o un artículo él lo equipara a un acto comunicativo. Por ejemplo "hay que llenar el reclamo de la amistad o de la cotidiana tarea o simplemente conceder un respiro a nuestro quehacer cotidiano... $\mathrm{y}$, deslizándonos por el terraplén del articulejo, dar fe de vida, demostrar que estamos en el mundo en ese momento y charlar" (Zamora Vicente 1983:47).

Una actividad importante de su vida consiste en relacionarse con sus alumnos, con la gente corriente y con sus iguales a través de un continuo hablar y escuchar, es decir, de una permanente actividad comunicativa. Quería poner énfasis en que, en relación con sus alumnos, la comunicación se produce siempre de un modo peculiar, original y, sobre todo, sumamente eficaz, yendo con frecuencia mucho más allá del contenido de la asignatura. Voy a dar testimonio de ello a través de mi propia experiencia. Por ejemplo, en clase, un tanto impertinente, yo critiqué que en la Facultad no se nos hablara de Hermann Hesse, Joyce, Bertold Bretch, Virginia Wolf, etc... que eran autores que con mis amigos estaba descubriendo entonces. Su respuesta fue, aparentemente, convencional, pero al salir de clase me pidió que lo acompañara a su casa, largo paseo en el que hablamos de lo humano y de lo divino y al llegar me invitó a subir y me prestó dos libros, el Jean Barois de Roger Martin du Gard (1913) y Le grand Meaulnes de Alain-Fournier (1913). Así, se inició una relación a través de la cual yo recibía un gran apoyo a las actividades culturales que llevábamos por nuestra cuenta un pequeño grupo de amigos, entre los que estaban Basilio Martín Patino y Manolo Bermejo. Hacíamos exposiciones de pintura y escultura; creamos un cine club que dirigía Patino; yo dirigía un grupo de teatro que representaba obras del siglo de oro y modernas como Antigona de Anouilh. Nos atrevimos, incluso, a publicar una revista estudiantil que llamamos El Gallo, en la que colaboraban personajes como Antonio Tovar, Fernando Lázaro Carreter, Gustavo Bueno y otros semejantes. Precisamente, le pedí a D. Alonso que nos escribiera un artículo y su respuesta fue una carta abierta que refleja fielmente los rasgos de su personalidad y el modo de relacionarse con sus alumnos. Como testimonio de ella se adjunta el contenido de la misma en Anexo.

Un rasgo de su talante comunicativo es la ironía que utiliza cuando quiere conjugar su actitud crítica, dura pero certera, a personas, situaciones o instituciones con su siempre clara disposición hacia lo positivo. Él mismo reconoce que tiene "fama 
de hombre burlón y atravesadillo" y que "el oficio me ha hecho gruñón, agrio, un tantico suspicaz" (Zamora Vicente 1953). Pero quiere dejar constancia de que "hoy permanece visible la estrecha corriente de simpatía y voluntad de entendimiento que ha flotado en todo cuando hemos podido hacer" (Zamora Vicente 1993:7). Y es que el talante comunicativo de D. Alonso le permite lo casi imposible: combinar la crítica mordaz o conmiserativa, la perspicacia, el humor que, a veces, se desliza hacia la caricatura, incluso, la sonrisa benevolente, por un lado, con la expresión de nostalgia del tiempo ido, la tristeza y el escepticismo derramándose (como diría él) y, por otro lado, con el aleteo de la esperanza, el gozo contemplativo y toda la gama de emociones humanas.

Una tercera característica de la actividad intelectual de Zamora Vicente es el objeto de la misma, aquello en lo que pensaba y de lo que hablaba continuamente. Ese objeto es la actividad lingüística, lo que él traduce para simplificar, a veces, como habla, otras como idioma y otras como lengua. Que esto es el objeto prioritario de la actividad intelectual de Zamora Vicente lo solía decir él mismo: "el habla sirve para retratar con indelebles apuntes una personalidad". En esta línea casi nos increpa: "urge seguir hablando, hablando a borbotones. Será prueba de que seguimos viviendo" (Zamora Vicente 1995:9). E insiste acerca de sus personajes: "su habla derramada a borbotones, apasionada e incongruente, arropada por la sintaxis de la emoción, los mantiene en pie" (Zamora Vicente 1995:7). En cualquier caso, en sus páginas "sea cual sea su signo o su meta, anda disimulado a veces, descaradamente en pie otras, el común hilo envolvente que las hace cuajar en flor de historia: el idioma" "ganando en español toda la tierra" (Zamora Vicente 1958:9), como dice el verso desnudado de César Vallejo.

\section{La importancia de la lengua en la vida y obra de Alonso Zamora Vicente}

Si me atengo a nuestro modelo pluridimensional de actividad lingüística, todas las dimensiones y sus interrelaciones han sido tratadas una y otra vez por D. Alonso. Tanto los sujetos de la producción como los de la comprensión, tanto el sistema lingüístico como el texto, tanto el texto como el contexto, tanto la modalidad hablada como la escrita, tanto las relaciones entre la actividad lingüística y la actividad cognitiva (especialmente el pensamiento) como las relaciones entre aquella y el componente emotivo. Ejemplos de la importancia que concede al habla para los sujetos de la misma acabamos de verlo. Podríamos añadir, refiriéndose a sus personajes: "Aquí se habla tan solo de pobre gente, gentes anónimas, atropelladas y charlatanas...... son tan solo voz, penuria lanzada al viento, escrita en el aire irrespirable de la precaria convivencia y dirigida a gritos a una formidable legión de sordos" (Zamora Vicente 1983:8). Respecto al sistema lingüístico, al español, defiende, por ejemplo, "la unidad de la lengua, férrea unidad espiritual bajo la que caben infinitas variantes locales, regionales y nacionales" (Zamora Vicente 1988:153). Pero cuando lo aplica a reflejar la realidad natural, social o psicológica (por ejemplo emocional) el sistema adquiere una dimensión sorprendente por su variedad, riqueza, precisión, originalidad y belleza: "grupo de muchachos y muchachas con su ropa nueva y sus ilusiones chillonas, canto, charla, risa pura, mientras en el aire adelgazado puede oírse a ¡qué bien suena! el caer sinuoso, zigzag lento, de una hoja amarilla" (Zamora Vicente 1984:44). En fin, como dice su amigo Cela: "Es grave que un hom- 
bre hable como un libro, pero es gozoso -aunque raro- que un hombre escriba con la llana lengua con la que habla" (Cela Trulock 1977:10).

\section{Alonso Zamora Vicente y su inserción en el contexto histórico}

No podemos seguir analizando otras características de la actividad intelectual de Zamora Vicente. Pero no nos resistimos a mencionar una muy significativa, que es su personal inserción en el contexto histórico que le tocó vivir y que, me atrevería a decir, es un rasgo definitivo de su personalidad, de su actividad intelectual y de su vida misma.

Y no voy a explicarlo ni analizarlo, porque, para terminar, creo que puede resumirse con sus propias palabras:

Mi generación al iniciar la vida profesional tras la guerra civil, se tropezó con un paisaje desolado, repleto de carencias, rotos los lazos con el ayer mimado. Disfrutamos de una Universidad gloriosa, como nunca ha habido en España, y había desaparecido. Quizás no nos dimos cuenta clara de lo que estaba pasando, pero el esfuerzo fue, si, consciente, en el momento de tomar decisiones. ¿Seríamos víctimas tristes de una inútil nostalgia? ¿Íbamos a recrearnos en la ruina, lamentándonos a horas preestablecidas....? No. Tomamos sin vacilar la decisión de proseguir por el camino elegido antes. Hubo de poner en marcha todo, anudar, por encima de lo visible, con aquello en lo que habíamos creído.

Y añade:

No estuve solo, María Josefa Canellada también supo lo que fueron esos días en que era casi delito reanudar una noble tradición. Nos correspondió, además, entregarnos a un enorme ejercicio de armonía colectiva, en una sociedad que había dado trágicas pruebas de no saber entenderse (Zamora Vicente 1993:6).

Que en este espejo de D. Alonso Zamora Vicente sepamos mirarnos y seguirle.

\section{Referencias bibliográficas}

Cela Trulock, Camilo José (1977): "Prólogo" a Alonso Zamora Vicente, Sin levantar cabeza. Madrid: Magisterio Español.

Zamora Vicente, Alonso (1958): Voz de la letra. Madrid: Espasa-Calpe.

Zamora Vicente, Alonso (1983): Estampas de la calle. Madrid: Ediamérica.

Zamora Vicente, Alonso (1984): Suplemento literario, introducción de Leonardo Romero Tobar. Madrid: Espasa-Calpe.

Zamora Vicente, Alonso (1988): Al trasluz de la lengua actual. Madrid: Universidad Complutense.

Zamora Vicente, Alonso (1993): La filología. Hablando con A. Zamora Vicente. Madrid: Acento Editorial.

Zamora Vicente, Alonso (1995): Hablan de la feria...Barcelona: Círculos de Lectores.

Zamora Vicente, Alonso (1995): Historias de viva voz. [Reedita 16 textos publicados en Mentirijillas]. Madrid: Alianza Editorial. 


\section{Apéndice}

Zamora Vicente, Alonso (1953): “Carta abierta a Juan Mayor”. El Gallo 1:2.

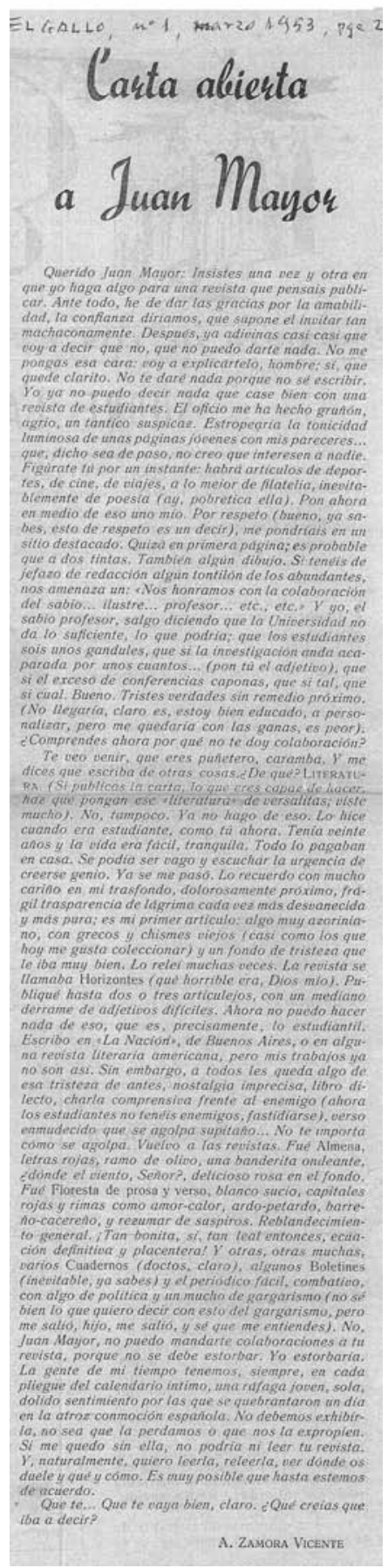

